\title{
Influence of Silicon, Carbon and Phosphorus on Intergranular Corrosion of High Purity Austenitic Stainless Steels Under Transpassive Conditions
}

\author{
J. Stolarz \\ Ecole Nationale Supérieure des Mines de Saint-Etienne, Centre SMS, URA 1884 du CNRS, 158 cours \\ Fauriel, 42023 Saint-Etienne cedex 2, France
}

\begin{abstract}
Precipitate-free Fe-Cr-Ni f.c.c. alloys exhibit strong intergranular corrosion in acid solutions at electrochemical potentials from the transpassivity range. Segregation of impurity atoms to grain boundaries is generally considered to be responsible for this specific kind of localized damage. A study of the influence of silicon, phosphorus and carbon on the intergranular transpassive corrosion of the solution treated $\mathrm{Fe}-17 \mathrm{Cr}-13 \mathrm{Ni}$ alloy in the $2 \mathrm{~N}$ sulphuric acid at a fixed electrochemical potential is presented. No localized attack occurs in a high purity base alloy nor in one containing phosphorus. The amount of intergranular corrosion is determined by the silicon content: according to previous results a maximum is observed for about $1 \mathrm{wt} . \%$ ( 2 at. \%) Si. Carbon additions between 100 and $200 \mathrm{ppm}$ cause some intergranular corrosion in silicon-free alloys and amplify the corrosion intensity in those containing silicon. No localized corrosion occurs for silicon contents higher than $2 \mathrm{wt} \%$. Au analysis of the segregation kinetics of silicon is presented and the relation between intergranular corrosion and bulk silicon concentration is discussed.
\end{abstract}

\section{INTRODUCTION}

Several $\mathrm{Fe}$ and Ni-base f.c.c. alloys exhibit a strong intergranular corrosion in acid solutions at electrochemical potentials from the transpassivity range. Very regular grain boundary grooves produced under these conditions (Fig.1) allow characterization of the extent of this localized damage by groove angles [1]. In all cases of transpassive corrosion, alloys can be considered as precipitate-free (high purity, high temperature heat treatment). Therefore, the origin of the phenomenon is different from that of the intergranular corrosion of "sensitized" stainless steels.

Intergranular segregation of silicon can be considered as the main factor in this localized attack in austenitic stainless steels [2]. However, phosphorus [3] and nitrogen [4] additions can also cause considerable modifications in the behaviour of alloys in regard to transpassive corrosion, in particular after low temperature heat treatments. Carbon contents of about $100-200$ wt.ppm can lead to an increase of the general corrosion rate of f.c.c. stainless steels in boiling nitric acid after treatment at $650^{\circ} \mathrm{C} \mathrm{[5].} \mathrm{On} \mathrm{the} \mathrm{other}$ hand, carbon concentrations near to $0.01 \%$ do not affect intergranular corrosion of solution treated f.c.c. steels [6].

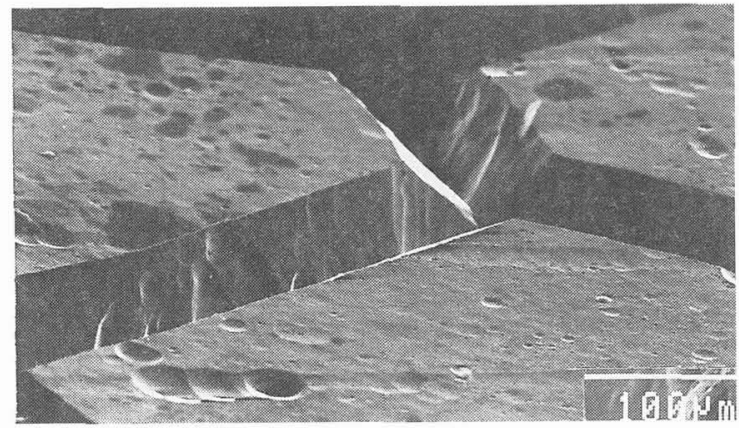

The aim of the present work is to analyse the influence of silicon $(0-4 \mathrm{wt} . \%)$, carbon $(10$ $200 \mathrm{ppm})$ and phosphorus (25- $100 \mathrm{ppm})$ on the intergranular transpassive corrosion of a high purity solution-treated $\mathrm{Fe}-17 \mathrm{Cr}-13 \mathrm{Ni}$ alloy. The kinetics of silicon segregation to grain boundaries will be discussed on the basis of potentiostatic corrosion tests carried out after heat treatments at various temperatures. Finally, an interpretation based on a possible segregation mechanism of silicon will be presented.

Figure 1: Intergranular corrosion under transpassive conditions in a Fe-Cr-Ni-Si alloy in $2 \mathrm{~N} \mathrm{H}_{2} \mathrm{SO}_{4}$ at $650 \mathrm{mV} / \mathrm{Hg}_{2} \mathrm{SO}_{4}$ 


\section{EXPERIMENTAL PROCEDURE}

Fe-base f.c.c. alloys containing $17-18 \mathrm{wt} . \% \mathrm{Cr}, 12-14 \mathrm{wt} . \% \mathrm{Ni}, 0-4 \mathrm{wt} . \% \mathrm{Si}$ and controlled carbon and phosphorus additions were prepared from high purity base metals in the laboratory of the Ecole des Mines de Saint-Etienne. Symmetrical $<001>20^{\circ}$ tilt bicrystals $(\mathrm{Fe}-17 \mathrm{Cr}-13 \mathrm{Ni}$ ) containing $1 \mathrm{wt} \%$ Si were prepared by the Chalmers method. Chemical compositions are given in Table 1.

Table 1: Chemical composition of alloys

\begin{tabular}{||l||c|c|c|c|c||}
\hline & Cr (wt. \%) & Ni (wt. \%) & Si (wt. \%) & C (wt. ppm) & P (wt. ppm) \\
\hline \hline Base alloy & 18.2 & 12.5 & $<0.05$ & 8 & $<25$ \\
\hline $50 \mathrm{P}$ & 18.6 & 14.0 & $<0.05$ & 8 & 65 \\
\hline $100 \mathrm{P}$ & 18.8 & 14.2 & $<0.05$ & 10 & 110 \\
\hline $100 \mathrm{P} 1 \mathrm{Si}$ & 18.6 & 13.9 & 1.5 & 7 & 115 \\
\hline $1 \mathrm{Si}$ & 18.9 & 13.9 & 0.8 & 7 & $<0,25$ \\
\hline \hline $100 \mathrm{C} 0 \mathrm{Si}$ & 17.8 & 14.8 & $<0.05$ & 85 & $<25$ \\
\hline $100 \mathrm{C} 0.3 \mathrm{Si}$ & 19.1 & 15.0 & 0.39 & 95 & $<25$ \\
\hline $100 \mathrm{C} 1 \mathrm{Si}$ & 17.3 & 13.7 & 1.05 & 80 & $<25$ \\
\hline \hline $200 \mathrm{C} 0 \mathrm{Si}$ & 18.5 & 12.1 & 0.10 & 160 & 150 \\
\hline $200 \mathrm{C} 0.2 \mathrm{Si}$ & 18.1 & 12.0 & 0.15 & 120 & 130 \\
\hline $200 \mathrm{C} 0.6 \mathrm{Si}$ & 18.0 & 12.3 & 0.65 & 150 & 150 \\
\hline $200 \mathrm{C} 1 \mathrm{Si}$ & 18.4 & 12.7 & 1.06 & 130 & 150 \\
\hline $200 \mathrm{C} 2 \mathrm{Si}$ & 18.4 & 12.1 & 2.12 & 160 & 180 \\
\hline $200 \mathrm{C} 4 \mathrm{Si}$ & 17.6 & 12.8 & 4.12 & 150 & 140 \\
\hline \hline bi $60 \mathrm{C} 0.8 \mathrm{Si}$ & 17.3 & 13.1 & 0.83 & 20 & $<25$ \\
\hline
\end{tabular}

All samples were given $1 \mathrm{~h}$ and $24 \mathrm{~h}$ treatments at $1200^{\circ} \mathrm{C}$ under argon, followed by water quenching. $<001>20^{\circ}$ tilt bicrystal and $1 \mathrm{Si}$ specimens used for the study of the segregation kinetics of silicon were treated for 24 hours at temperatures between $550^{\circ} \mathrm{C}$ and $1000^{\circ} \mathrm{C}$, then water quenched. All surfaces were prepared by mechanical polishing before corrosion tests.

Potentiostatic transpassive corrosion tests were carried out in $2 \mathrm{~N}$ sulphuric acid solution in water at 650 $\mathrm{mV} / \mathrm{Hg}_{2} \mathrm{SO}_{4}$ for 24 hours. In addition, some corrosion tests in a boiling $14.4 \mathrm{~N}$ nitric acid solution at free electrochemical potential with potential monitoring were performed.

In all cases, intergranular grooves observed by SEM had a triangular section (Fig.1) and their angle is independent of time at a constant electrochemical potential. The groove angles were measured on SEM micrographs using a method described in [7]. Stability of groove angles is linked to a constant value of the ratio of dissolution rates of bulk alloy $V_{s}$ and of grain boundaries $V_{j}$. The specific dimensionless intergranular corrosion intensity is defined by the following equation [2]:

$$
\mathrm{J}=(\sin \alpha / 2)^{-1}-1
$$

The corrosion intensity $\mathrm{J}$ is equal to zero if no intergranular groove is produced and it increases when grooves become "sharper". The groove angles were measured on SEM micrographs using a method described in [7]. As shown in [2] for silicon containing stainless steels, this criterion of the corrosion intensity allows comparison of intergranular segregation levels between different grain boundaries and between alloys of different silicon content.

\section{RESULTS}

Table 2 presents intergranular corrosion intensities $\mathrm{J}$ (mean values from about 30 measurements) for all solution treated polycrystalline alloys .

The results of the corrosion tests can be summarized as follows:

* For high purity $\mathrm{P}$ and $\mathrm{P} / \mathrm{Si}$ alloys, no difference between $1 \mathrm{~h}$ and $24 \mathrm{~h}$ treatments is observed. $1 \mathrm{Si}$ and 1Si $100 \mathrm{P}$ alloys exhibit strong intergranular corrosion. 
Phosphorus alone (100 ppm) does not cause intergranular corrosion and its addition to the alloy silicon containing does not modify its corrosion behaviour.

* In $100 \mathrm{C}$ alloys, intergranular corrosion is only observed for silicon contents approaching $1 \mathrm{wt} . \%$. Corrosion intensities $J$ are a little higher than in carbon free alloys but they are independent of treatment time.

* In $200 \mathrm{C} / \mathrm{Si}$ alloys, intergranular corrosion is observed even for very low silicon contents. Corrosion intensity $\mathrm{J}$ reaches its maximum for about $1 \mathrm{wt}$. \% Si, then it decreases rapidly so that no intergranular grooves are observed for $2 \mathrm{wt}$ \% Si. In the $200 \mathrm{C} 1 \mathrm{Si}$ alloy, intergranular corrosion is stronger than for $1 \mathrm{Si}$ alloys with lower carbon contents. On the other hand, a small increase of $\mathrm{J}$ is produced by the $24 \mathrm{~h}$ treatment at $1200^{\circ} \mathrm{C}$.

Table 2: Intergranular corrosion intensities $J$ after corrosion tests in sulphuric acid

\begin{tabular}{|c|c|c|c|c|c|}
\hline & $1 \mathrm{~h} / 1200^{\circ} \mathrm{C}$ & $24 \mathrm{~h} / 1200^{\circ} \mathrm{C}$ & & $1 \mathrm{~h} / 1200^{\circ} \mathrm{C}$ & $24 \mathrm{~h} / 1200^{\circ} \mathrm{C}$ \\
\hline Base & $\overline{\overline{0}}$ & $\overline{\overline{0}}$ & $100 \mathrm{C} 1 \mathrm{Si}$ & $\overline{0.60}$ & 0.62 \\
\hline $50 \mathrm{P}$ & $\overline{0}$ & $\overline{0}$ & $200 \mathrm{C} \mathrm{OSi}$ & 0.22 & 0.22 \\
\hline $100 \mathrm{P}$ & 0 & 0 & $200 \mathrm{C} 0.2 \mathrm{Si}$ & 0.21 & 0.27 \\
\hline 100P 1Si & 0.52 & 0.55 & $200 \mathrm{C} 0.6 \mathrm{Si}$ & 0.41 & 0.56 \\
\hline $1 \mathrm{Si}$ & 0.48 & 0.50 & $200 \mathrm{C} 1 \mathrm{Si}$ & 0.64 & 0.86 \\
\hline $100 \mathrm{C} \mathrm{OSi}$ & 0 & 0 & $200 \mathrm{C} 2 \mathrm{Si}$ & $\overline{0}$ & 0 \\
\hline $100 \mathrm{C} 0.3 \mathrm{Si}$ & 0 & 0 & $200 \mathrm{C} 4 \mathrm{Si}$ & $\overline{0}$ & 0 \\
\hline
\end{tabular}

Table 3 presents the results of intergranular corrosion tests for the $1 \mathrm{Si}$ alloy and for the $60 \mathrm{C} 0.8 \mathrm{Si}$ bicrystal after 24 hours' treatment between 550 and $1200^{\circ} \mathrm{C}$.

Table 3: Intergranular corrosion intensities $J$ after heat treatments between 550 and $1200^{\circ} \mathrm{C}$

\begin{tabular}{|l||c|c|c|c|c|}
\hline & $1200^{\circ} \mathbf{C}$ & $1000^{\circ} \mathbf{C}$ & $75 \overline{0}^{\circ} \mathbf{C}$ & $\mathbf{6 5 0}^{\circ} \mathbf{C}$ & $\mathbf{5 5 0}^{\circ} \mathbf{C}$ \\
\hline 1Si & $0.50 \pm 0.20$ & $0.52 \pm 0.25$ & N.A. & $0.45 \pm 0.12$ & $0.56 \pm 0.20$ \\
\hline bi 60C 0.8Si & $1.00 \pm 0.10$ & $0.89 \pm 0.16$ & $0.95 \pm 0.15$ & $0.95 \pm 0.12$ & $1.04 \pm 0.16$ \\
\hline
\end{tabular}

Surprisingly, almost no temperature dependence of $\mathrm{J}$ is observed. It seems that only treatments at $550^{\circ} \mathrm{C}$ produce a small increase of corrosion intensity compared to all other temperatures.

\section{DISCUSSION}

The present study confirms the influence of silicon on transpassive corrosion of solution-treated f.c.c. alloys. However, if silicon segregation is generally considered to be responsible for the formation of intergranular grooves, no study of the segregation process has been presented up to now. In particular no satisfactory explanation of the corrosion maximum near to $1 \mathrm{wt} \% \mathrm{Si}$ has been given. In our previous paper [2], the existence of a linear relation between corrosion intensity $\mathrm{J}$ and the intergranular concentration of silicon was shown by means of Auger spectroscopy. It can be therefore concluded that potentiostatic transpassive corrosion tests can be used to compare intergranular segregation levels of silicon in different alloys.

Supposing that the segregation of silicon is an equilibrium process, it is possible to use the classical McLean's segregation model. Using the version of the model proposed by Nowicki and Biscondi [8], it is possible to give the relation between intergranular $c_{j}$ and bulk $c_{v}$ concentrations of the segregating species:

$$
\frac{c_{j}}{c_{j}{ }^{0}-c_{j}}=\frac{c_{v}}{1-c_{v}} \exp \left(-E_{s} / k T\right)
$$

with: $c_{j} 0$ - ratio of number of possible segregation seats and of total intergranular seats per unit surface of grain boundary (maximum grain boundary occupation by

$\mathrm{E}_{\mathrm{s}} \quad-\quad$ segregating atoms); 
An estimation of the segregation energy can be made only if $c_{j} 0$ is known. According to computer simulation of intergranular structures and of the intergranular segregation of substitution atoms in f.c.c. lattice, it is possible to calculate $c_{j} \mathrm{O}(\mathrm{Si})$ for different $<001>$ tilt boundaries [9]. It is found that the occupation level of grain boundaries can vary from about $0.08\left(<001>20^{\circ}\right)$ to $0.17\left(<001>37^{\circ}\right)$. An estimation of $E_{S}$ made for a $<001>20^{\circ}$ tilt boundary gives $-0.40 \pm 0.05 \mathrm{eV} / \mathrm{atom}$ [6] for cj 0 equal to 0.11 . It is therefore possible to predict the intergranular segregation of silicon as a function of its bulk concentration and of temperature. Figure 2 presents the results of this estimation.

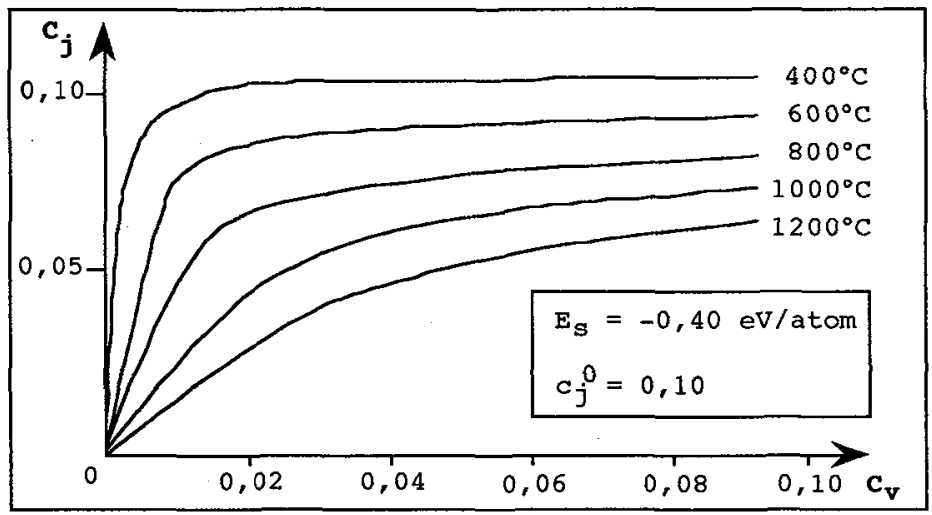

Figure 2: Temperature dependence of silicon concentration at grain boundaries - theoretical estimation

If the segregation model is correct, a very strong temperature dependence of integranular concentration of silicon should be observed, in particular for silicon contents approaching 2 at. \%.

In order to explain the discrepancies between the theoretical predictions (Fig.2) and experimental results (Tab. 3), an analysis of the segregation kinetics of silicon was attempted. A kinetic relation based on Mc Lean's model allows to estimate the time necessary to obtain intergranular concentration of segregating atoms equal to $90 \%$ of its equilibrium value $\left(t_{s} 90\right)$ :

$$
\mathrm{t}_{\mathrm{s}} 90 \approx 30,8 \frac{\mathrm{B}^{2} \mathrm{~d}^{2}}{4 \mathrm{D}}
$$

with: $B$ - boundary enrichment factor $\left(c_{j} / c_{V} c_{j}\right)^{0}$;

d - boundary width $\left(\mathrm{d} \approx 5 \cdot 10^{-8} \mathrm{~cm}\right)$;

$D$ - diffusion coefficient $(D=f(T))$.

An estimation of $\mathrm{t}_{\mathrm{s}}{ }^{90}$ for $\mathrm{a}<001>20^{\circ}$ tilt boundary for $\mathrm{c}_{\mathrm{v}}=0.02$ in the temperature range between 400 and $1200^{\circ} \mathrm{C}$ is presented in Table 4.

Table 4: Estimation of the intergranular segregation kinetics of silicon

\begin{tabular}{||c||c|c|c|c|c|}
\hline Temperature [ $\left.{ }^{\circ} \mathbf{C}\right]$ & 1200 & 1000 & 800 & 600 & 400 \\
\hline $\mathbf{D}_{\mathbf{v}}(\mathbf{S i})\left[\mathbf{c m}^{\mathbf{2}} \mathbf{s}^{-1}\right]$ & $6.5 \cdot 10^{-10}$ & $5.5 \pm 10^{-11}$ & $2.0 \cdot 10^{-12}$ & $1.8 \cdot 10^{-14}$ & $2.0 \cdot 10^{-17}$ \\
\hline $\mathbf{t}_{\mathbf{s}} \mathbf{s 0}^{\mathbf{1 0}}[\mathbf{s}]$ & $3.1 \cdot 10^{-3}$ & $4.0 \cdot 10^{-2}$ & 1 & 100 & $10^{5}$ \\
\hline
\end{tabular}

Segregation times are very short for temperatures above about $600^{\circ} \mathrm{C}$. This is particularly due to a low $\mathrm{B}$ factor. The results shown in Table 4 indicate that it is very difficult to obtain experimentally equilibrium concentrations of silicon at grain boundaries corresponding to higher temperatures. On the other hand, heat treatments at temperatures lower than $600^{\circ} \mathrm{C}$ do not lead to much boundary enrichment, as can be seen from Figure 2. All results of intergranular corrosion tests performed after a solution treatment at $1200^{\circ} \mathrm{C}$ should therefore be considered as representing the segregation behaviour of silicon at a much lower temperature (probably between 600 and $800^{\circ} \mathrm{C}$ ).

The maximum intergranular corrosion intensity J observed at about $1 \mathrm{wt} . \%$ Si $(\approx 2$ at. \%) can also be explained on the basis of the segregation behaviour of silicon. Figure 3 shows the theoretical evolution of 
the boundary enrichment $\mathrm{c}_{\mathrm{j}} / \mathrm{c}_{\mathrm{v}}$ with the bulk concentration of silicon for $800^{\circ} \mathrm{C}$. For silicon contents higher than $2 \mathrm{wt} \%(\approx 4$ at.\%), the difference between nominal and intergranular chemical composition becomes very small.

According to the equation (2), intergranular corrosion is the result of a difference between dissolution rates of the boundary zone and of adjacent grains. Experimental results show (Table 2 - base alloy) that perturbation of the atomic arrangement at grain boundaries without segregation is not sufficient to produce a significant difference of dissolution rates of both zones. If one assumes that this difference is produced mainly by modifications of chemical compositions of both zones, figure 3 shows clearly that no specific grain boundary dissolution can occur for silicon contents higher than $2 \mathrm{wt}$. \%.

A study of the relation between dissolution rate and silicon content can also explain the existence of the peak of intergranular corrosion intensity near to $1 \mathrm{wt}$.\%. Figure 4 shows an approximative relation of general corrosion rate in $2 \mathrm{~N}$ sulphuric acid vs. silicon content. Between 0 and $1 \mathrm{wt}$ \% $\%$ Si, no influence of silicon is observed. For silicon contents between 1 and $4 \mathrm{wt} . \%(2-8$ at. $\%)$, general corrosion rate increases almost linearly.

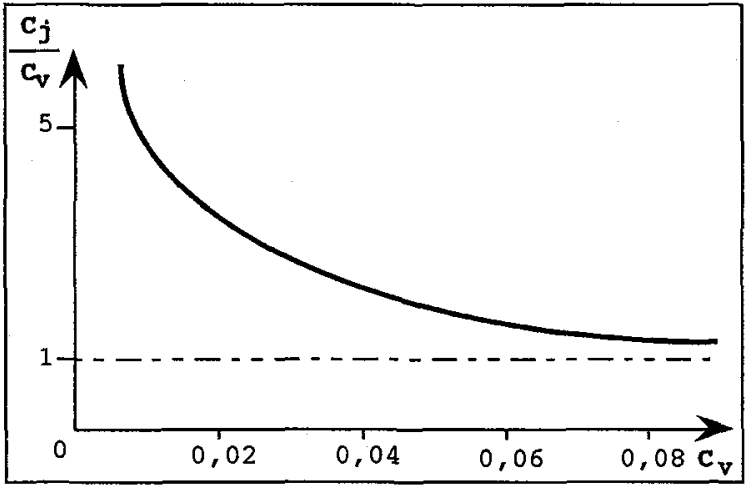

Figure 3: Grain boundary enrichment at $800^{\circ} \mathrm{C}$ vs. bulk silicon content (atomic fraction) for a $<001>20^{\circ}$ symmetrical tilt boundary

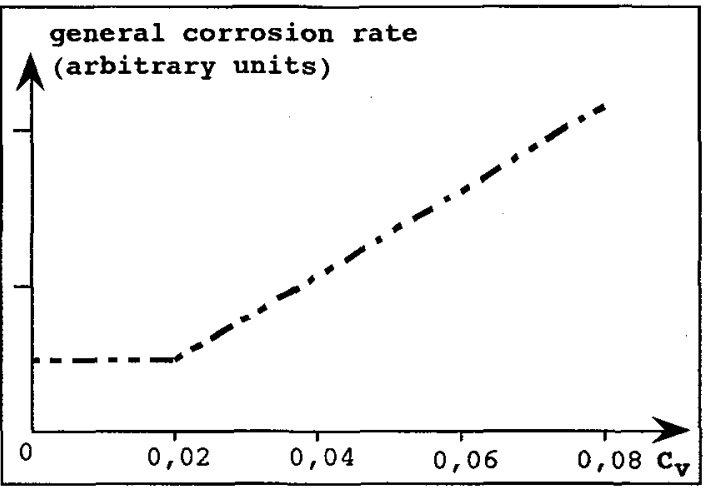

Figure 4: General corrosion rate (weight loss) in silicon containing austenitic stainless steels vs. silicon concentration [9]

The results of figures 3 and 4 give, finally, the relation between intergranular corrosion intensity $J$ and silicon concentration of alloy. This relation (Fig.5) is in excellent agreement with experimental results, particularly in regard to the position of the corrosion peak near to $1 \mathrm{wt} . \% \mathrm{Si}$.

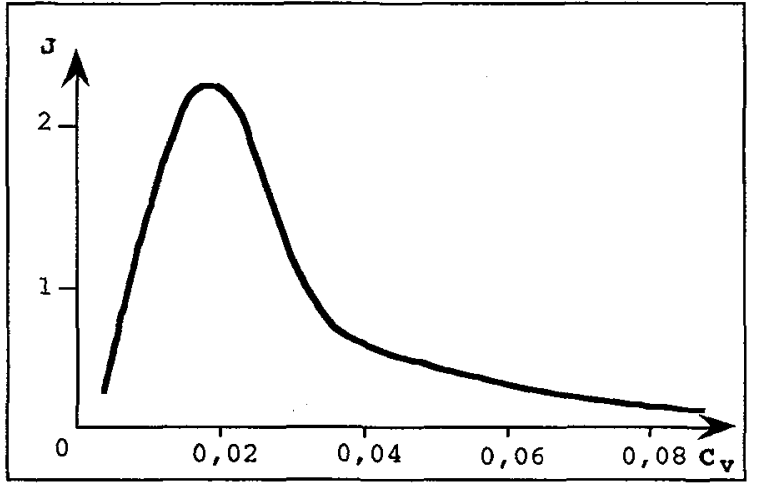

Figure 5: Intergranular corrosion intensity $J$ in sulphuric acid vs. Si content-predistion for $800^{\circ} \mathrm{C}$ based on general corrosion tests

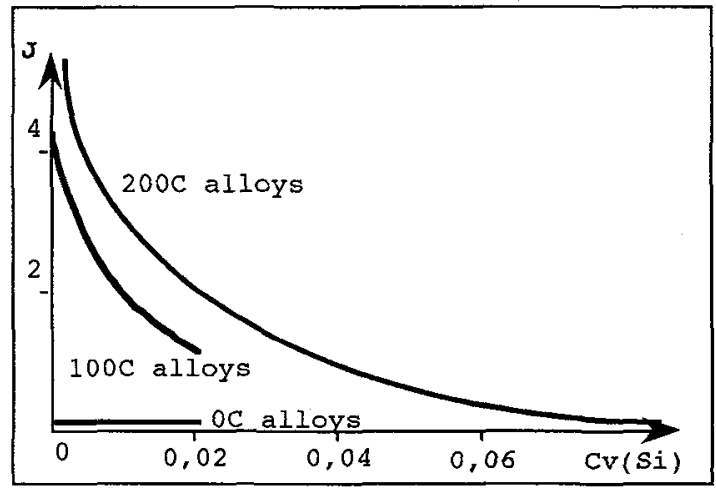

Figure 6: Intergranular corrosion intensity $J$ in nitric acid Influence of carbon and silicon after 24 hours treatment at $1200^{\circ} \mathrm{C}$ and water quenching

The results shown in the present paper do not lead to any conclusion about the influence of carbon on intergranular corrosion af ter solution treatment at $1200^{\circ} \mathrm{C}$. It seems that possible carbon segregation has no influence on intergranular corrosion for $C$ less than $100 \mathrm{wt}$. ppm. On the other hand, the results from Table 
2 show that carbon contents approaching $200 \mathrm{ppm}$ lead to intergranular corrosion even for very low silicon levels. Intergranular dissolution in the $200 \mathrm{C}$ OSi alloy can only be explained if carbon segregation is taken into account even if no direct experimental evidence is available. In addition to this, only $200 \mathrm{C}$ alloys (Table 2) show some increase of intergranular corrosion intensity $\mathrm{J}$ with time of solution treatment at $1200^{\circ} \mathrm{C}$.

The influence of carbon is strongly enhanced in another kind of transpassive corrosion tests - in a boiling 14.4N $\mathrm{HNO}_{3}$ solution with potential monitoring [7]. In this test, intergranular corrosion intensity depends very strongly on carbon content. Results shown in Figure 6 show that silicon alone does not cause any intergranular corrosion. On the other hand, in $200 \mathrm{C}$ alloys, intergranular dissolution is most intense in silicon free alloy and it decreases progressively with growing silicon content (Fig.6). In all alloys containing carbon tested in nitric acid, the intensity of intergranular corrosion increases vs. time of treatment at $1200^{\circ} \mathrm{C}$.

If carbon segregation is responsible for integranular corrosion in nitric acid, a possible explanation could be based on a competition between silicon and carbon segregations to grain boundaries. Since silicon segregation is extremely fast, the process takes place before carbon segregation becomes possible. It cannot be excluded that carbon segregation to boundaries already containing silicon becomes more difficult and less carbon can migrate to boundaries than in Si-free alloys. This kind of process was observed in $\mathrm{Fe}-$ alloys with controlled phosporus, carbon and nitrogen contents $[4,10]$.

The differences of corrosion behaviour in sulphuric and nitric acid tests are possibly related to the nature of electrochemical reactions at the surface of the alloy in both environments. On the other hand, electrochemical conditions are very different in both tests (imposed potential in sulphuric acid and free potential in $\mathrm{HNO}_{3}$ ) even if in both cases potentials are from the transpassivity range.

\section{CONCLUSION}

Corrosion tests of f.c.c. Fe-base alloys with controlled silicon, carbon and phosphorus contents confirm the influence of silicon on intergranular corrosion under transpassive conditions.

Transpassive corrosion of grain boundaries in stainless steels results from intergranular segregation and not from the difference between activation energies of dissolution induced by the perturbation of atomic arrangement in grain boundaries compared to an ideal crystal.

On the basis of direct evidence of silicon presence in grain boundaries [2], segregation kinetics was analysed by measurements of corrosion groove angles after different heat treatments. Due to a low enrichment factor of silicon in grain boundaries, the segregation process is extremely fast at temperatures below $1000^{\circ} \mathrm{C}$. This explains why almost no temperature dependence of silicon segregation is observed experimentally. An analysis of relation between intergranular and bulk silicon contents leads to a theoretical prediction of an intergranular corrosion peak at $1 \mathrm{wt}$.\% Si. This result, observed experimentally by many authors, has never been explained before.

The influence of carbon on the integranular corrosion of solution treated alloys seems to be more complex. In alloys containing carbon, the intensity of intergranular corrosion depends on time of heat treatment at $1200^{\circ} \mathrm{C}$. On the other hand, corrosion tests in nitric acid show that the presence of carbon at grain boundaries has to be taken into account when analyzing integranular corrosion, even if no direct experimental evidence for carbon segregation is available.

\section{References}

[1] Beaunier L. and Froment M., C.R.Acad.Sci.Paris C, 279 (1974) 91-94.

[2] Stolarz J. and Le Coze J., Colloque de Physique C1, 51 (1990) 641-645.

[3] Mullford R.A., Hall E.L. and Briant C.L., Corrosion, 39 (1983) 132-143.

[4] Erhart H. and Grabke H-J., Scr.Metall., 15 (1981) 531-534.

[5] Hochörtler G. and Horn E.M., Congrès International de Corrosion Métallique, Toronto, Vol.3 (1984) p.444.

[6] Armijo J.S., Corrosion, 24 (1968) 24-30.

[7] Stolarz J., Le Coze J. anf Désestret A., $9^{\text {th }}$ European Congress on Corrosion, Utrecht, Vol.1 (1989) FU-227.

[8] Nowicki T., Joud J-C. and Biscondi M, Colloque de Physique C1, 51 (1990) 293.

[9] Stolarz J., Corrosion d'aciers inoxydables austénitiques au silicium dans les conditions transpassives PhD Thesis EMP-EMSE, Saint-Etienne (1989).

[10] Suzuki S. et al., Scr.Metall., 17 (1983) 1325-1328. 